\title{
Validation and implementation of a patient-reported experience measure for patients with rheumatoid arthritis and spondyloarthritis in the Netherlands
}

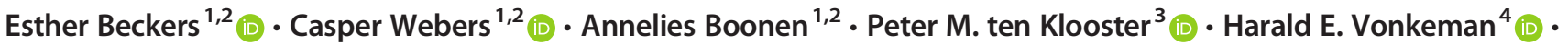 \\ Astrid van Tubergen ${ }^{1,2}$ (D)
}

Received: 5 December 2019 / Revised: 24 March 2020 / Accepted: 1 April 2020 / Published online: 21 April 2020

(C) The Author(s) 2020

\begin{abstract}
Objectives To test the psychometric properties of the United Kingdom's Commissioning for Quality in Rheumatoid Arthritis Patient-Reported Experience Measure (CQRA-PREM) in patients with spondyloarthritis (SpA) and rheumatoid arthritis (RA) and to implement this questionnaire in daily practice in the Netherlands.

Methods After a forward-backward translation procedure into Dutch, the CQRA-PREM was tested into two quality registries in daily practice. Face validity was assessed with focus group interviews. Feasibility was evaluated through completion times and interpretability of domain scores through floor and ceiling effects. Internal consistency (Cronbach's $\alpha$ coefficients) and homogeneity (corrected item-total correlations) were determined. Divergent validity was assessed by Spearman's rank correlation coefficients $\left(r_{\mathrm{s}}\right)$ between the average scores of domains and outcome measures. The CQRA-PREM was implemented in daily practice, and the results were used in quality improvement cycles.

Results Face validity of the CQRA-PREM was good. The CQRA-PREM was completed by 282 patients with SpA and 376 with RA. Median time to complete the CQRA-PREM was $4.7 \mathrm{~min}$. Ceiling effects were found in three out of seven domains. Internal consistency of nearly all domains was considered good $(0.65 \leq \alpha \leq 0.95)$. Thresholds for homogeneity were exceeded within three domains $\left(r_{\mathrm{p}}>0.7\right)$, suggesting item redundancy. Divergent validity showed that nearly all domains of the CQRA-PREM were at most weakly correlated with outcomes measures $\left(-0.3 \leq r_{\mathrm{s}} \leq 0.3\right)$. The CQRA-PREM could identify areas of improvement for providing patient-centered care.

Conclusion The CQRA-PREM has acceptable psychometric properties and has shown to be a useful tool in evaluating quality of care from the patients' perspective in the Netherlands.

Trial registration SpA-Net is registered in the Netherlands Trial Registry (NTR6740).

\section{Key Points}

- The Commissioning for Quality in Rheumatoid Arthritis Patient-Reported Experience Measure (CQRA-PREM) is a valid measure for assessing patient-centeredness of rheumatology care.

- The Dutch version of the CQRA-PREM shows acceptable psychometric properties.

- The CQRA-PREM shows to be a useful tool in Plan-Do-Check-Act quality improvement cycles in the Netherlands.

- The CQRA-PREM can be used for benchmarking and quality improvement of rheumatology services.
\end{abstract}

Electronic supplementary material The online version of this article (https://doi.org/10.1007/s10067-020-05076-6) contains supplementary material, which is available to authorized users.

Esther Beckers

esther.beckers@mumc.nl

1 Department of Internal Medicine, Division of Rheumatology, Maastricht University Medical Center, P. Debyelaan 25, 6229 HX, Maastricht, The Netherlands
2 Care and Public Health Research Institute (CAPHRI), Maastricht University, Maastricht, Netherlands

3 Department of Psychology, Health \& Technology, University of Twente, Enschede, Netherlands

4 Department of Rheumatology, Medisch Spectrum Twente, Enschede, Netherlands 
Keywords Epidemiology $\cdot$ Outcome research $\cdot$ Patient perspective $\cdot$ Rheumatoid arthritis $\cdot$ Spondyloarthritis

\section{Introduction}

Evaluating the quality of care provided is helpful to reveal areas of improvement of care, identify best practices and stimulate development and implementation of care innovations. Health care services should also be transparent with respect to care provided, as decision-makers, society and patients have the right to know about the quality of the services available to them [1]. The Institute of Medicine (IOM) identifies six pillars for evaluating quality of care in the current health care system: care that is provided should be safe, effective, patient-centered, timely, efficient, and equitable [2]. Patientcentered care is gaining more attention in the last decade and has become a key part of audits of care organizations [3]. Patient-centered care is defined by the IOM as care that is respectful of, and responsive to, individual patient preferences, needs, and values and ensures that patient values guide all clinical decisions [2]. It is organized around the health needs and expectations of patients rather than around diseases.

There are several advantages of applying patient-centered care in daily practice. A literature overview showed that patient-centered care in patients with rheumatoid arthritis (RA) improved clinical safety and effectiveness [4]. Another study showed that better patient care experiences were associated with higher levels of adherence to treatment [5]. In addition, a patient-centered approach by family physicians and general internists in primary care was associated with decreased utilization of health care services and lower annual medical charges [6]. Therefore, it is important that patients should be asked about their experienced care and improve this where necessary.

Patients' perspectives on care provided within a certain time period can be evaluated with patient-reported experience measures (PREMs), which focus on aspects of care that matter to patients and thereby identify areas of improvement for health care services. PREMs assess patients' experiences relating to the structure and/or process of care provided and might include questions relating to outcomes of care provided. PREMs can assess quality of care for the generic population or for a disease-specific population. Disease-specific PREMs are preferred for assessing quality of care provided as generic PREMs might not cover aspects of care that are specific and weighted toward a particular condition [7].

Currently, there are two measures available for assessing patients' experiences with rheumatic care in the Netherlands: the Consumer Quality Index for patients with Rheumatoid Arthritis (CQ-Index RA) and the Quality of Care Through the Patients' Eye for all Rheumatic Patients (QUOTERheumatic-Patients) $[8,9]$. Both questionnaires are generic measures for assessing the quality of care provided in all health care services available to patients with RA and include the importance patients award to each aspect of quality of care.

However, both questionnaires have several limitations. First, the CQ-Index RA and QUOTE-Rheumatic-Patients contain a large number of questions (115 and 155 questions, respectively), which might be too time-consuming. Second, the CQ-Index RA is disease-specific for RA and therefore not applicable to other rheumatic diseases. Third, both measures are generic for health care services and are not specifically developed for rheumatology services.

In the United Kingdom (UK), a PREM has been developed by the Commissioning for Quality in Rheumatoid Arthritis Patient-Reported Experience Measure (CQRA-PREM) to evaluate patients' perspectives on care provided in rheumatology units in the UK National Health Service (NHS) [10]. This questionnaire has been developed and validated in RA, modified and validated in other rheumatic conditions, and has been in use since 2015 [10, 11]. The CQRA-PREM includes 23 questions in seven domains aligned to the National Health Service Patient Experience Framework (NPEF) for patientcentered care and one question for evaluating the overall experience of the care provided [10]. The framework of the CQRA-PREM represents the most salient issues in patients' experiences with hospital care for RA patients and is widely used for assessing patients' experiences with care provided in several rheumatology units [12-14]. The NPEF domains can be used to identify specific areas of improvement from the patients' perspective within care departments. The implementation of the CQRA-PREM in rheumatology units was found to be effective in this regard [10].

Currently, a feasible PREM that is applicable to different rheumatic diseases in the setting of the rheumatology unit is lacking in the Netherlands. The primary aim of our study was to test the psychometric properties of the CQRA-PREM by performing qualitative and quantitative analyses in Dutch patients with SpA and RA. A secondary aim was to implement the CQRA-PREM in daily practice in the Netherlands. The results of the questionnaire were evaluated in quality improvement cycles for patient-centeredness of care.

\section{Methods}

\section{PREM translation}

The CQRA-PREM is categorized into seven NPEF domains for patient-centered care (one to five items per domain). Answers are given on a 5-point Likert scale ranging from "strongly disagree" to "strongly agree" (online resources 1 
and 2) [15]. Detailed information on the development and validation of the CQRA-PREM can be found elsewhere [10].

The UK version of the CQRA-PREM was independently translated into Dutch by two native Dutch-speaking researchers fluent in English (one rheumatologist and one health care scientist). Discrepancies were discussed, and a consensus version was generated by both forward translators. The consensus version was back-translated by another bilingual Dutch researcher (a methodologist) with no prior knowledge of the questionnaire. A final version was developed by all three translators and was checked by an additional Dutch researcher unfamiliar with the original questionnaire (a rheumatologist).

\section{Face validity}

Face validity of the CQRA-PREM was studied by performing semi-structured focus group interviews with patients. Aspects of patient-centered care that were important to patients and their current experiences with patient-centered care were assessed. A sample of adult patients from the rheumatology outpatient clinic of the Maastricht University Medical Center (MUMC+) was invited to participate. Interviews were planned with approximately five patients per group, until data saturation was reached. Face validity was assessed by comparing aspects of care that were important to patients with domains of the CQRA-PREM.

\section{Field testing}

The psychometric properties of the CQRA-PREM were tested in two ongoing, prospective, disease-specific real-life quality registries in daily practice for patients with $\mathrm{SpA}$ and RA in the Netherlands, SpA-Net and DREAM-RA, respectively, in two medical centers (MUMC+ and Medisch Spectrum Twente) in different geographical areas in the Netherlands [16, 17]. Patients in these registries have a clinical diagnosis of SpA or RA and were consecutively included by their rheumatologist. In both registries, outcome measures, results of clinical examinations and laboratory investigations are routinely collected at every outpatient visit through a web-based data collection and quality management application (www. mijnreumacentrum.nl). Outcome measures consist of validated measures of disease activity, physical function and overall health status.

In SpA-Net, disease activity is measured with the Bath Ankylosing Spondylitis Disease Activity Index (BASDAI) and Ankylosing Spondylitis Disease Activity Score (ASDAS) with C-Reactive Protein [18, 19], physical functioning with the Bath Ankylosing Spondylitis Functional Index (BASFI), Health Assessment Questionnaire for Spondyloarthritis (HAQ-S) [20, 21], and disease impact with the Assessment of Spondyloarthritis International Society Health Index score (ASAS HI) [22]. In DREAM-RA, disease activity is measured with the Disease Activity Score for 28 joints with Erythrocyte Sedimentation Rate (DAS28) [23] and physical functioning with the Health Assessment Questionnaire (HAQ) [24]. In both SpA-Net and DREAMRA, overall health status is assessed with the self-report MOS 36-Item Short Form Health Survey (SF36), resulting in physical component summary (PCS) and mental component summary (MCS) scores [25].

Starting from December 2016, patients from the two medical centers participating in SpA-Net and DREAM-RA were invited to annually complete the CQRA-PREM upon logging in to the application. Questionnaires were only saved if they were fully completed. Patients were informed that individual results are not visible for physicians or nurses. In the current cross-sectional analysis, the most recently completed CQRAPREM from each patient was included for analyses. Results from outcome measures were included if they were completed within 14 days before or after completing the CQRA-PREM. For measures completed more than once within the 14-day timeframe, the measurement closest in time to the CQRAPREM administration was selected.

\section{Implementation and quality improvement}

After translation and validation, the CQRA-PREM was implemented in daily practice. Through repeated Plan-DoCheck-Act (PDCA) quality improvement cycles, the results from the CQRA-PREM representing the patients' perspective on quality of provided care were evaluated at several occasions with rheumatologists and rheumatology nurses from both medical centers. This was followed by group discussions to identify areas for improvement. Several action plans were formulated and executed in clinical practice where possible.

\section{Statistical analysis}

Descriptive statistics were used to describe characteristics of participants of the focus group interviews, of patients who completed the CQRA-PREM in the patient registries, and to describe the relative frequencies of scores in the CQRAPREM for patients with SpA or RA.

All focus group interviews were audiotaped and transcribed verbatim. In NVIVO V.11, the editing analysis style was used to analyze all transcripts by structurally classifying meaningful quotes into themes and subthemes. Finally, aspects of care that were important for patients were summarized and results were interpreted. Details about the patient inclusion procedure and data analyses have been described elsewhere [17].

In addition to face validity, the following elements of the COSMIN (COnsensus-based Standards for the selection of health status Measurement INstruments) checklist for evaluating the methodological quality of studies on measurement 
properties were examined: feasibility, interpretability, and internal consistency [26]. Furthermore, homogeneity and divergent validity were also tested.

Feasibility of the CQRA-PREM was determined by calculating the median (interquartile range (IQR)) time patients needed to complete the questionnaire. Interpretability of the CQRA-PREM was evaluated by testing floor and ceiling effects in the average scores of the domains needs and preferences, coordination of care, information about care, daily living and physical comfort, and emotional support, thereby considering the categorical 5-point Likert scores as linear. Floor and ceiling effects were considered to be present if $15 \%$ or more of the patients had the lowest or highest possible average domain score [27].

Internal consistency of a single assessment of the CQRAPREM was studied within domains containing more than two questions with correlation analyses (Cronbach's $\alpha$ coefficients) and was considered good if $0.70 \leq \alpha \leq 0.95$ [28]. Homogeneity within domains containing more than two questions was studied with corrected item-total correlations $\left(r_{\mathrm{p}}\right)$ to identify questions with very weak or very strong correlations within the respective domain and was considered good if $0.30 \leq\left(r_{\mathrm{p}}\right) \leq 0.70$ [29].

Divergent validity was studied through non-parametric Spearman's rank correlation coefficients $\left(r_{\mathrm{s}}\right)$ with average scores of domains and outcome measures for disease activity, daily functioning, health status, and quality of life. Since PREMs are assumed to capture something different than the patient's condition or outcomes of treatment alone, and in accordance with studies evaluating PREMs in other medical conditions [30], correlations with patient-reported outcomes and clinical outcomes were hypothesized to be weak at most $\left(-0.30 \leq r_{\mathrm{s}} \leq 0.30\right)$, indicating that the measures evaluate relatively distinct constructs [31].

All analyses, except for face validity, were repeated in patients stratified for the use of biologic disease-modifying antirheumatic drugs (bDMARDs) at the time of completing of the CQRA-PREM. Statistical analyses were performed using IBM SPSS Statistics 24.

\section{Results}

The CQRA-PREM was completed by 282 patients with SpA and 376 patients with RA. The average age and the relative number of female patients with SpA were lower compared with patients with RA (52.7 ( $\mathrm{SD}=12.3$ ) versus $61.5(\mathrm{SD}=$ 11.9 ) years and $47.9 \%$ versus $64.9 \%$ female patients, respectively (Table 1). The median disease duration was 8.6 (min
Table 1 Demographic characteristics and outcome measures of patients in SpA-Net and DREAM-RA

\begin{tabular}{|c|c|c|}
\hline & $\begin{array}{l}\text { SpA-Net } \\
(n=282)\end{array}$ & $\begin{array}{l}\text { DREAM-RA } \\
(n=376)\end{array}$ \\
\hline Age, years & $52.7(12.3)$ & $61.5(11.9)$ \\
\hline Female, $n(\%)$ & $135(47.9)$ & $244(64.9)$ \\
\hline Symptom duration, years, median (min-max) & $12.9(0.6-67.5)$ & NA \\
\hline Disease duration, years, median (min-max) & $8.6(0.0-66.5)$ & $7.7(0.0-44.0)$ \\
\hline bDMARD use, $n(\%)$ & $155(55.0 \%)$ & $112(29.8 \%)$ \\
\hline \multicolumn{3}{|l|}{ Disease activity } \\
\hline BASDAI [0-10] & $4.3(2.2)$ & - \\
\hline ASDAS $[0-\infty]$ & $2.2(0.9)$ & - \\
\hline DAS28 $[0-\infty]$ & - & $2.3(1.2)$ \\
\hline \multicolumn{3}{|l|}{ Physical function } \\
\hline HAQ-S [0-3] & $0.8(0.6)$ & $0.8(0.7)$ \\
\hline BASFI $[0-10]$ & $3.2(2.4)$ & - \\
\hline ASAS HI [0-19] & $5.7(3.5)$ & - \\
\hline \multicolumn{3}{|l|}{ Overall health status } \\
\hline SF36 PCS [0-100] & $39.9(10.4)$ & $40.9(9.6)$ \\
\hline SF36 MCS $[0-100]$ & $48.7(11.2)$ & $50.5(10.8)$ \\
\hline
\end{tabular}

Values expressed as mean (SD), unless otherwise indicated

bDMARDs biologic Disease-Modifying Antirheumatic Drugs, BASDAI Bath Ankylosing Spondylitis Disease Activity Index, ASDAS Ankylosing Spondylitis Disease Activity Score with C-Reactive Protein, $D A S 28$ Disease Activity Score for 28 joints, HAQ-S Health Assessment Questionnaire for Spondyloarthritis, $H A Q$ Health Assessment Questionnaire, BASFI Bath Ankylosing Spondylitis Functional Index, ASAS HI Assessment of Spondyloarthritis international Society Health Index, SF36 Medical Outcomes Study 36Question Short Form, PCS Physical Component Summary, MCS Mental Component Summary, $S p A$ Spondyloarthritis, $R A$ Rheumatoid Arthritis, $S D$ Standard Deviation, NA Not Available 
0.0, max 66.5) years for patients with $\mathrm{SpA}$ and 7.7 (min 0.0, $\max 44.0$ ) years for patients with RA. Use of bDMARDs was $55.0 \%$ in patients with $\mathrm{SpA}$ and $29.8 \%$ in patients with RA. On average, disease activity was high for patients with $\mathrm{SpA}$ but low for patients with RA.

Both study populations experienced on average mild difficulties in physical functioning (mean HAQ-S $=0.8(\mathrm{SpA})$ and mean $\mathrm{HAQ}=0.8(\mathrm{RA})$ ). The overall health status related to physical health and mental health was comparable in patients with $\mathrm{SpA}$ and patients with RA (mean SF36 PCS $=39.9$ in SpA and mean SF36 PCS $=40.9$ in RA and mean SF36 MCS $=48.7$ in SpA and mean SF36 MCS $=50.5$ in RA).

The distribution of the scores on the CQRA-PREM was skewed towards positive, indicating that patients have positive experiences with care, and is shown separately for patients with $\mathrm{SpA}$ and RA in online resources 1 and 2.

\section{Face validity}

Semi-structured focus group interviews were performed to assess the face validity of the CQRA-PREM. Four focus group interviews were performed with 16 patients (3-5 patients per interview), after which information saturation was reached. Median age of the participants was 62.6 (41-78) years, median symptom duration 17.5 (1-66) years, and 6 $(37.5 \%)$ were male. The patients identified the following eight aspects as important for providing patient-centered care: (1) feeling heard by care providers, (2) being involved in shared decision making, (3) being able to visit the same care provider over time, (4) being able to contact care providers when needed, (5) feeling satisfied with the quality of answers, (6) being easily referred to other specialists when needed, (7) having the feeling that there is enough time during appointments, and (8) having appointments on time. Nearly all these aspects are covered by the CQRA-PREM, except having appointments on time.

\section{Psychometric properties}

The median time to complete the CQRA-PREM was $4.7 \mathrm{~min}$ $(\mathrm{IQR}=2.4)$ in the total population $(4.7 \mathrm{~min}(\mathrm{IQR}=2.7)$ in SpA-Net and $4.6 \mathrm{~min}(\mathrm{IQR}=2.3$ ) in DREAM-RA). Interpretability assessed by floor and ceiling effects in average scores of domains showed ceiling effects $(\geq 15 \%)$ in the domains needs and preferences for both patients with SpA and RA and in the domains daily living and physical comfort and emotional support for patients with RA (Table 2). Internal consistency of all domains was considered good for patients with $\mathrm{SpA}$ or RA, except for the domain daily living and physical comfort in patients with RA $(\alpha=0.65)$ (Table 2). Homogeneity was considered good for each question in the domains information, education, and self-care and daily living and physical comfort for both patients with $\mathrm{SpA}$ and RA

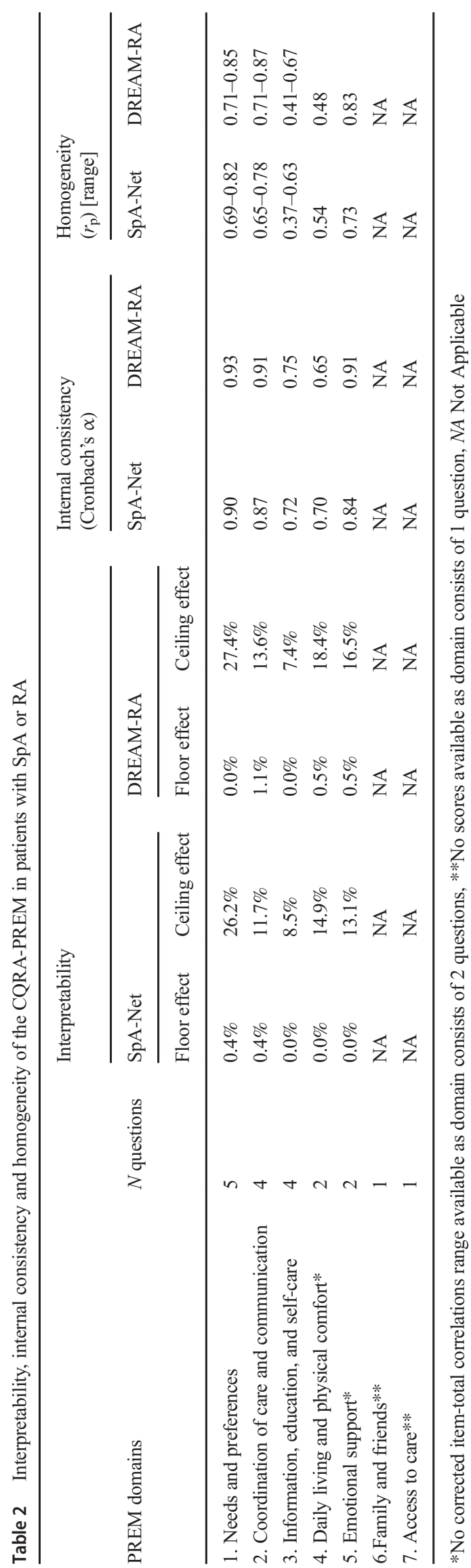


$\left(0.3 \leq\left(r_{\mathrm{p}}\right) \leq 0.7\right)$. However, thresholds for homogeneity were exceeded $\left(r_{\mathrm{p}}>0.7\right)$ by two or more questions within the remaining domains for patients with SpA or RA (Table 2 and online resource 3 ). The divergent validity showed that, as expected, nearly all domains of the CQRA-PREM were at most weakly correlated with patient-reported outcomes ($0.30 \leq r_{\mathrm{s}} \leq 0.30$ ) (Table 3).

Patient demographic characteristics and outcome measures were comparable between patients with or without bDMARD use (online resource 4); however, the median disease duration was higher in bDMARD users compared with non-bDMARD users, both in RA and SpA. The median time to complete the CQRA-PREM did not differ between both subgroups (data not shown).

Scores for interpretability and internal consistency were comparable between bDMARD and non-bDMARD users. However, homogeneity differed between patients with and without bDMARDs in both SpA and RA (online resources 5 and 6). Scores for divergent validity were also comparable between bDMARD and non-bDMARD users, except for the domains access to care and overall experience with care with all outcome measures in patients with $\mathrm{SpA}$ (online resources 7 and 8).

In both patients with RA and SpA without bDMARD use, the correlations between these two domains and all outcome measures were, in general, higher compared with patients with bDMARD use, however, at most weakly correlated.

\section{Implementation}

In the PDCA cycles, the CQRA-PREM identified the domain information, education, and self-care as an important area of improvement for patients with SpA and RA. Several adjustments in care were made to improve this domain. For example, every new patient with SpA or RA now receives a business card with contact information from his/her treating rheumatologist and is referred to a rheumatology nurse for education. The rheumatology nurse brings under attention the possibility of following a self-management course and supports the patient who is starting a disease-modifying antirheumatic drug. In addition, the awareness about patient organizations, patient groups and self-management programs was further increased by providing leaflets and projecting information on screens in the waiting room.

\section{Discussion}

In this study, we demonstrated that the CQRA-PREM has valid psychometric properties in patients with SpA and RA in clinical practice. In addition, we showed that the CQRAPREM is a useful tool for assessing the patient-centeredness

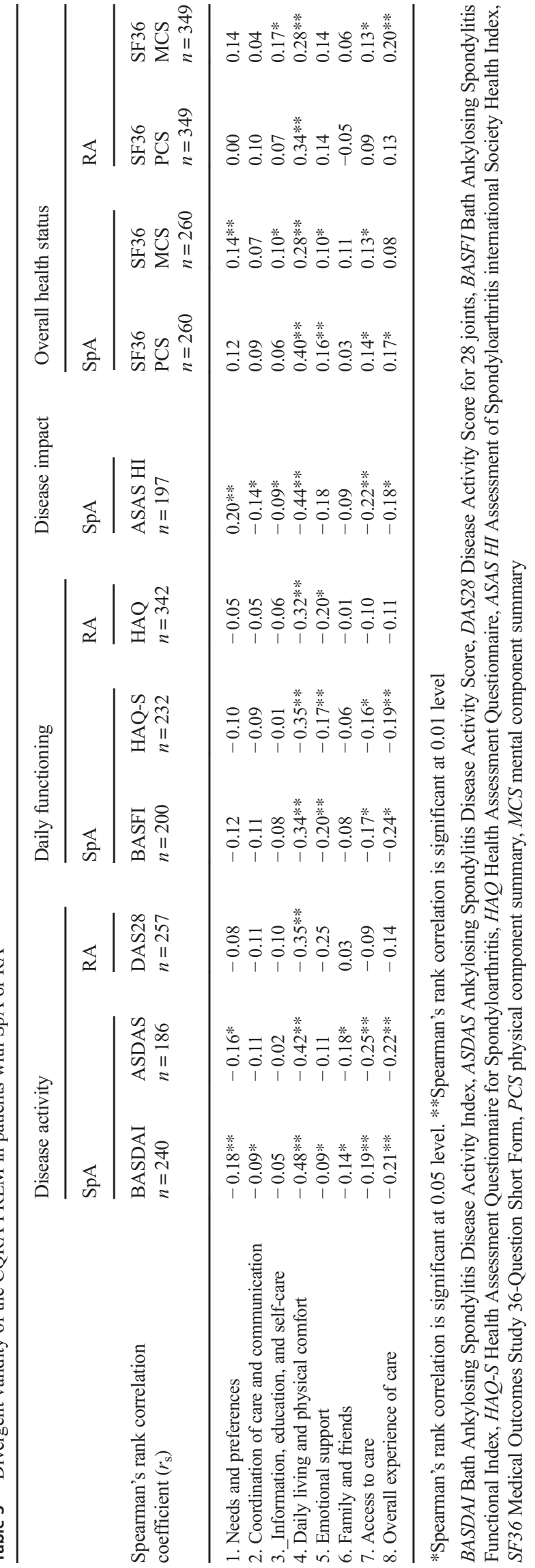


of care provided and that it is able to identify areas of improvement in a Dutch rheumatology setting.

The CQRA-PREM showed good face validity as aspects that were rated as important to Dutch patients were similar to those raised by patients in the UK. The CQRA-PREM also covers all indicators from the Dutch QUOTE-RheumaticPatients [9]. However, the CQ-Index RA includes one domain specifically related to experiences with provided information about medication, which is missing in the CQRA-PREM. On the other hand, the CQRA-PREM includes two domains, friends and family and information, education, and self-care, that are not addressed in both the CQ-Index RA and QUOTERheumatic-Patients.

Feasibility of the CQRA-PREM was considered acceptable with a median completion time of 4.7 minutes. The homogeneity of the CQRA-PREM showed exceeded thresholds in three domains. This suggests that some questions are redundant within domains. However, our results for internal consistency did not differ from the original development study, both in RA patients ( $\alpha=0.65$ to $\alpha=0.93$ (DREAM-RA) versus $\alpha=0.61$ to $\alpha=0.90)$ and in SpA patients $(\alpha=0.70$ to $\alpha=$ 0.90 (SpA-Net) versus $\alpha=0.76$ to $\alpha=0.91$ ) [10]. Interpretability of the CQRA-PREM showed ceiling effects for the domains needs and preferences, daily living and physical comfort, and emotional support, which implies that the interpretability of the CQRA-PREM is not valid enough. However, these results could reflect true patients' experiences, and thus satisfaction with care provided or social desirability bias could have occurred, despite the fact that patients were made aware that results were not visible for physicians and nurses [29]. Moreover, ceiling effects are common in patient experience measures, in contrast with scores for outcome measures [32].

Subgroup analyses were performed in patients with or without bDMARD use at the time of completing the PREM, as hypothetically these patients might have different experiences with provided care. Our study showed that results for feasibility, interpretability, internal consistency, and nearly all analyses for divergent validity were comparable between these groups. Despite the fact that scores for homogeneity differed slightly between these groups, the overall validity of the CQRA-PREM was acceptable in both subgroups.

The Dutch version of the CQRA-PREM was field-tested in two patient registries, and therefore patients might provide higher scores for question $2 \mathrm{~d}$ (I feel that the people I see at the clinic are fully up to date with my current situation), which could result in selection bias. However, it is expected that this has a minimal effect on the validity of the domain information, education, and self-care, because it is not solely related to this information but also to having received information on time and receiving enough information to make decisions. Results for the domain coordination and communication are not biased by field testing in the patient registers, because patients cannot directly contact their care providers through our registries as there is no email functionality in the system. We therefore believe that field testing in patient registries has resulted in only limited selection bias and that the CQRA-PREM can also be used in patients in standard care.

Evaluating the quality of care with PREMs, in addition to Patient-Reported Outcome Measures (PROMs), is important as they measure different aspects of quality of care. PREMs assess patients' perspectives on the structure and process of provided care, while PROMs specifically assess patients' perspectives on the outcomes of provided care. Besides that, patients' perspectives on the quality of provided care might differ from the perspective of health care professionals. As we did in our study, PREMs can be used by care providers to reflect on their own and their team's performance, indicate specific areas of improvement at clinical and organizational levels, and can be used to evaluate the impact of introduced changes within organizations. Patients benefit from PREMs as it helps them to choose high quality care providers when results for quality of care are made transparent for the public.

This study has several limitations. First, no cognitive debriefing with native Dutch-speaking patients was performed and no cross-cultural validity was assessed. However, besides the three translators, one additional native speaker was included to check the final Dutch version for linguistic and cultural accuracy. Second, no factor analyses were performed to support that the allocation of questions into domains is similar in the Dutch version as in the original CQRA-PREM. However, all translators agreed that each domain of the NPEF is represented by the allocated questions in the Dutch version of the questionnaire. Third, the psychometric properties test-retest reliability, sensitivity-to-change over time, and convergent validity could not be examined in this study. These aspects could be evaluated in further studies, as well the ability of the CQRA-PREM to discriminate between rheumatology units who have more or less attention for providing patient-centered care. Fourth, we acknowledge that selection bias could have occurred due to the registries' webbased design as patients with low health literacy and/or computer skills might have been excluded from this study. Fifth, the CQRA-PREM did not include a free text field for additional remarks from patients who wanted to elaborate on their results or offer possible solutions for aspects that could be improved in their experiences. Although analyzing these additional remarks in a mixed method approach might be timeconsuming, it could provide valuable information for the rheumatic care services.

A strength of our study is that the translation and validation of the CQRA-PREM were combined with focus group interviews to test face validity and with implementation of the measure in daily practice with which, through PDCA cycles, areas for improvement were identified and acted upon. A second strength of this study is that the CQRA-PREM was tested in two real-life 
registries for $\mathrm{SpA}$ and RA in the Netherlands. We were able to validate the questionnaire in daily practice and study divergent validity with recorded outcome measures for disease activity, physical functioning, and overall health status.

In conclusion, the CQRA-PREM has acceptable psychometric properties for assessing quality of care provided in daily practice from the perspective of patients with $\mathrm{SpA}$ or RA in the Netherlands. Scores for quality of care provided are not substantially affected by outcome measures for disease activity, physical functioning and overall health status. The CQRA-PREM has shown to be a useful tool in PDCA quality improvement cycles and can be used to optimize patientcentered care in rheumatic health care services as recommended by the IOM.

Acknowledgments The authors gratefully acknowledge Martijn Oude Voshaar for his input in the translational process of the CQRA-PREM to Dutch and Yvonne van Eijk for her contribution to the focus group interviews.

Authors' contributions $\mathrm{AB}, \mathrm{HV}, \mathrm{PtK}$, and AvT designed the study; EB, $\mathrm{CW}$, and AvT were involved in the data acquisition and/or management; EB, PtK, and AvT analyzed the data and critically interpreted the results; EB and AvT were involved in drafting the manuscript. All authors revised the manuscript critically for important intellectual content and approved the final manuscript.

Funding information SpA-Net was financially supported by grants from ZonMw (project number 836042001) and Dutch Arthritis Society and was sponsored by AbbVie, Biogen, Celgene, Janssen-Cilag, MSD, Novartis, Pfizer, and UCB.

Data availability Additional analyses can be performed upon reasonable request. Contact the principle investigator (a.van.tubergen@mumc.nl) for more information.

\section{Compliance with ethical standards}

Disclosures None.

Ethical approval The ethics committee of the academic hospital Maastricht/University Maastricht determined that the Medical Research Involving Human Subjects Act did not apply and official approval was not required for this study.

Informed consent Informed consent was obtained to use the patients' data in SpA-Net for research purpose and separately for the focus group interviews.

Open Access This article is licensed under a Creative Commons Attribution 4.0 International License, which permits use, sharing, adaptation, distribution and reproduction in any medium or format, as long as you give appropriate credit to the original author(s) and the source, provide a link to the Creative Commons licence, and indicate if changes were made. The images or other third party material in this article are included in the article's Creative Commons licence, unless indicated otherwise in a credit line to the material. If material is not included in the article's Creative Commons licence and your intended use is not permitted by statutory regulation or exceeds the permitted use, you will need to obtain permission directly from the copyright holder. To view a copy of this licence, visit http://creativecommons.org/licenses/by/4.0/.

\section{References}

1. WHO (2015) World Health Organization Global strategy on people-centred and integrated health services: World Health Organizations; [Available from: https://www.who.int/ servicedeliverysafety/areas/people-centred-care/global-strategy/ en/. Accessed 22 Feb 2019

2. IOM (2001) Institute of medicine crossing the quality chasm: a new health system for the 21 st century. National Academy Press, Washington

3. van Dijkhuizen E, Egert T, Egert Y, Costello W, Schoemaker C, Fernhout M, Kepic M, Martini A, Scala S, Rotstein-Grein I, Vastert SJ, Wulffraat NM (2018) Patient's experiences with the care for juvenile idiopathic arthritis across Europe. Pediatr Rheumatol Online J 16(1):10

4. Voshaar M, Nota I, van de Laar M, van den Bemt B (2015) Patientcentred care in established rheumatoid arthritis. Best Pract Res Clin Rheumatol 29(4-5):643-663

5. Anhang Price R, Elliott MN, Zaslavsky AM, Hays RD, Lehrman WG, Rybowski L, Edgman-Levitan S, Cleary PD (2014) Examining the role of patient experience surveys in measuring health care quality. Med Care Res Rev 71(5):522-554

6. Bertakis K, Azari R (2011) Determinants and outcomes of patientcentered care. Patient Educ Counss 85(1):46-52

7. Walker S, Andrew S, Hodson M, Roberts CM (2017) Stage 1 development of a patient-reported experience measure (PREM) for chronic obstructive pulmonary disease (COPD). NPJ Prim Care Respir Med 27(1):47

8. Zuidgeest M, Sixma H, Rademakers J (2009) Measuring patients' experiences with rheumatic care: the consumer quality index rheumatoid arthritis. Rheumatol Int 30(2):159-167

9. van Campen C, Sixma H, Kerssens J, Peters L, Rasker J (1998) Assessing patients' priorities and perceptions of the quality of health care: the development of the QUOTE-Rheumatic-Patients instrument. Br J Rheumatol 37(4):362-368

10. Bosworth A, Cox M, O'Brien A, Jones P, Sargeant I, Elliott A, Bukhari M (2015) Development and validation of a patient reported experience measure (PREM) for patients with rheumatoid arthritis (RA) and other rheumatic conditions. Curr Rheumatol Rev 11(1): $1-7$

11. Bosworth A, Elliott A, O'Brien A, Sargeant I, Bukhari M, Cox M et al (2014) Modification of a validated patient-reported experience measure tool for rheumatoid arthritis for use in other rheumatic conditions: results of a pilot study. Rheumatology 53(suppl 1): i93-ii4

12. Jenkinson C, Coulter A, Bruster S (2002) The picker patient experience questionnaire: development and validation using data from in-patient surveys in five countries. Int J Qual Health Care 14(5): 353-358

13. Jenkinson C, Coulter A, Gyll R, Lindstrom P, Avner L, Hoglund E (2002) Measuring the experiences of health care for patients with musculoskeletal disorders (MSD): development of the picker MSD questionnaire. Scand J Caring Sci 16(3):329-333

14. Rathert C, Williams ES, McCaughey D, Ishqaidef G (2015) Patient perceptions of patient-centred care: empirical test of a theoretical model. Health Expect 18(2):199-209

15. Gerteis M, Edgman-Levitan S, Daley J, Delbanco TL, Hobbins TE (1995) Through the patient's eyes: understanding and promoting patient-centered care. J Nerv Ment DisJ Nerv Ment Dis 183(7):488 
16. Kievit W, Fransen J, Oerlemans AJ, Kuper HH, van der Laar MA, de Rooij DJ, de Gendt CM, Ronday KH, Jansen TL, van Oijen P, Brus HL, Adang EM, van Riel P (2007) The efficacy of anti-TNF in rheumatoid arthritis, a comparison between randomised controlled trials and clinical practice. Ann Rheum Dis 66(11):1473-1478

17. Webers C, Beckers E, Boonen A, van Eijk-Hustings Y, Vonkeman H, van de Laar M, van Tubergen A (2019) Development, usability and acceptability of an integrated eHealth system for spondyloarthritis in the Netherlands (SpA-Net). RMD Open 5(1): $\mathrm{e} 000860$

18. Lukas C, Landewe R, Sieper J, Dougados M, Davis J, Braun J et al (2009) Development of an ASAS-endorsed disease activity score (ASDAS) in patients with ankylosing spondylitis. Ann Rheum Dis 68(1):18-24

19. Garrett S, Jenkinson T, Kennedy LG, Whitelock H, Gaisford P, Calin A (1994) A new approach to defining disease status in ankylosing spondylitis: the Bath Ankylosing Spondylitis Disease Activity Index. J Rheumatol 21(12):2286-2291

20. Calin A, Garrett S, Whitelock H, Kennedy LG, O'Hea J, Mallorie P, Jenkinson T (1994) A new approach to defining functional ability in ankylosing spondylitis: the development of the Bath Ankylosing Spondylitis Functional Index. J Rheumatol 21(12):2281-2285

21. Daltroy LH, Larson MG, Roberts NW, Liang MH (1990) A modification of the Health Assessment Questionnaire for the Spondyloarthropathies. J Rheumatol 17(7):946-950

22. Kiltz U, van der Heijde D, Boonen A, Akkoc N, Bautista-Molano W, Burgos-Vargas R, Wei JC, Chiowchanwisawakit P, Dougados M, Duruoz MT, Elzorkany BK, Gaydukova I, Gensler LS, Gilio M, Grazio S, Gu J, Inman RD, Kim TJ, Navarro-Compan V, MarzoOrtega H, Ozgocmen S, Pimentel Dos Santos F, Schirmer M, Stebbings S, van den Bosch F, van Tubergen A, Braun J (2018) Measurement properties of the ASAS health index: results of a global study in patients with axial and peripheral spondyloarthritis. Ann Rheum Dis 77(9):1311-1317

23. Prevoo ML, van 't Hof MA, Kuper HH, van Leeuwen MA, van de Putte LB, van Riel PL (1995) Modified disease activity scores that include twenty-eight-joint counts. Development and validation in a prospective longitudinal study of patients with rheumatoid arthritis. Arthritis Rheum 38(1):44-48

24. Bruce B, Fries JF (2003) The Stanford Health Assessment Questionnaire: dimensions and practical applications. Health Qual Life Outcomes 1:1-20

25. Ware J, Sherbourne C (1992) The MOS 36-item short-form health survey (SF-36). I. Conceptual framework and item selection. Med Care 30(6):473-483

26. Mokkink LB, Terwee CB, Patrick DL, Alonso J, Stratford PW, Knol DL et al (2010) The COSMIN checklist for assessing the methodological quality of studies on measurement properties of health status measurement instruments: an international Delphi study. Qual Life Res 19(4):539-549

27. McHorney CA, Tarlov AR (1995) Individual-patient monitoring in clinical practice: are available health status surveys adequate? Qual Life Res 4(4):293-307

28. Terwee CB, Bot SD, de Boer MR, van der Windt DA, Knol DL, Dekker J, Bouter LM, de Vet HC (2007) Quality criteria were proposed for measurement properties of health status questionnaires. J Clin Epidemiol 60(1):34-42

29. Streiner DL, Norman GR, Cairney J (2015) Health measurement scales: a practical guide to their development and use, 5th edn. Oxford University Press, New York

30. Black N, Varaganum M, Hutchings A (2014) Relationship between patient reported experience (PREMs) and patient reported outcomes (PROMs) in elective surgery. BMJ Qual Saf 23(7):534-542

31. Mukaka MM (2012) Statistics corner: a guide to appropriate use of correlation coefficient in medical research. Malawi Med J 24(3): 69-71

32. Sjetne IS, Bjertnaes OA, Olsen RV, Iversen HH, Bukholm G (2011) The generic short patient experiences questionnaire (GS-PEQ): identification of core items from a survey in Norway. BMC Health Serv Res 11:88

Publisher's note Springer Nature remains neutral with regard to jurisdictional claims in published maps and institutional affiliations. 